\title{
$\underline{\mathbf{P}-149}$
}

\section{Discrimination of Alternanthera Sessilis of Different Origins in Malaysia Using FT-IR and Two-Dimensional Infrared Correlation Spectroscopy and Multivariate Data Analysis}

\author{
Siti Shahrul Nazifah Razak ${ }^{\mathrm{b}}$, Siti Mutheerah Abdaziz ${ }^{\mathrm{b}}$, Son Radu ${ }^{\mathrm{b}}$, Faridah Abas ${ }^{\mathrm{a}}$, Victor Neto ${ }^{\mathrm{a}}$ and \\ Alfi Khatib, ${ }^{\mathrm{a}, \mathrm{b}, *}$ \\ ${ }^{a}$ Laboratory of Natural Product, Institute of Bioscience, University Putra Malaysia, 43400 UPM, Serdang, Selangor, \\ Malaysia; ${ }^{b}$ Faculty of Food Science and Technology, University Putra Malaysia, 43400 Serdang, Selangor Darul \\ Ehsan, Malaysia; E-mail: alfikhatib@yahoo.com
}

Alternanthera sessilis is one of the herbal medicines used in Malaysia especially among Chinese race. The metabolite fingerprinting analysis of ethanolic extracts of leaves of A.sessilis was carried out using Fourier-transform infrared (FTIR) spectroscopy in combination with multivariate data analysis to differentiate between four different origins of plant harvested. Principle component analysis (PCA) of the infrared spectra showed an obvious cluster between origin 1(from Putrajaya) and origin 3 (from Rantau Panjang), meanwhile, origin 2 (from Serdang) and 4 (from Ampang) is almost closer by PC1 and PC2 (99.2\% and $0.4 \%$ total variance, respectively) score plots. The results of PLS-DA similar with the PCA result. The samples were further analyzed using two-dimensional infrared correlation spectroscopy and the results showed remarkable differences between samples of different origins.

Keywords: Alternanthera sessilis, FT-IR, 2D-IR, Multivariate data analysis, Metabolomics, multivariate data analysis. 